\title{
The prevalence of opportunistic infections and malignancies in autopsied patients with human immunodeficiency virus infection in Japan
}

Harutaka Katano ${ }^{1 *}$, Tsunekazu Hishima ${ }^{2}$, Makoto Mochizuki ${ }^{3,4}$, Yoshinori Kodama ${ }^{5}$, Naoki Oyaizu ${ }^{6}$, Yasunori Ota ${ }^{6}$, Sohtaro Mine ${ }^{1,3}$, Toru Igari ${ }^{3}$, Atsushi Ajisawa ${ }^{7}$, Katsuji Teruya ${ }^{8}$, Junko Tanuma ${ }^{8}$, Yoshimi Kikuchi ${ }^{8}$, Tomoko Uehira ${ }^{9}$, Takuma Shirasaka ${ }^{9}$, Tomohiko Koibuchi ${ }^{10}$, Aikichi Iwamoto ${ }^{10,11}$, Shinichi Oka ${ }^{8}$, Hideki Hasegawa', Seiji Okada ${ }^{12}$ and Akira Yasuoka ${ }^{13}$

\begin{abstract}
Background: Opportunistic infections and malignancies such as malignant lymphoma and Kaposi sarcoma are significant complications of human immunodeficiency virus (HIV) infection. However, following the introduction of antiretroviral therapy in Japan in 1997, the incidence of clinical complications has decreased. In the present study, autopsy cases of HIV infection in Japan were retrospectively investigated to reveal the prevalence of opportunistic infections and malignancies.

Methods: A total of 225 autopsy cases of HIV infection identified at 4 Japanese hospitals from 1985-2012 were retrospectively reviewed. Clinical data were collected from patient medical records.

Results: Mean CD4 counts of patients were 77.0 cells/ $\mu \mathrm{L}$ in patients who received any antiretroviral therapy during their lives (ART ( + ) patients) and 39.6 cells/ $\mu \mathrm{L}$ in naïve patients (ART (-) patients). Cytomegalovirus infection (142 cases, 63.1\%) and pneumocystis pneumonia (66 cases, 29.3\%) were the most frequent opportunistic infections, and their prevalence was significantly lower in ART (+) patients than ART (-) patients. Non-Hodgkin lymphoma and Kaposi sarcoma were observed in $30.1 \%$ and $16.2 \%$ of ART (-) patients, and $37.9 \%$ and $15.2 \%$ of ART (+) patients, respectively. Malignant lymphoma was the most frequent cause of death, followed by cytomegalovirus infection regardless of ART. Non-acquired immunodeficiency syndrome (AIDS)-defining cancers such as liver and lung cancer caused death more frequently in ART (+) patients (9.1\%) than in ART $(-)$ patients $(1.5 \%$; $P=0.026)$.

Conclusions: The prevalence of infectious diseases and malignancies were revealed in autopsy cases of HIV infection in Japan. The prevalence of cytomegalovirus infection and pneumocystis pneumonia at autopsy were lower in ART (+) patients than ART (-) patients. Higher prevalence of non-AIDS defining malignancies among ART (+) patients than ART (-) patients suggests that onsets of various opportunistic infections and malignancies should be carefully monitored regardless of whether the patient is receiving ART.
\end{abstract}

Keywords: AIDS, Opportunistic infections, Autopsy, Antiretroviral therapy

\footnotetext{
* Correspondence: katano@nih.go.jp

${ }^{1}$ Department of Pathology, National Institute of Infectious Diseases, 1-23-1

Toyama, Shinjuku-ku, Tokyo 162-8640, Japan

Full list of author information is available at the end of the article
} 


\section{Background}

Opportunistic infections such as Pneumocystis jirovecii pneumonia (PCP), cytomegalovirus (CMV), non-tuber culous mycobacteria (NTM), and fungal infections are frequently found in patients with acquired immunodeficiency syndrome (AIDS) [1]. The most frequent opportunistic infection among patients with AIDS is CMV infection, which commonly causes retinitis, pneumonia, and gastrointestinal tract ulcers. PCP is also a frequent infectious disease in the lungs of patients with AIDS. Additionally, malignancies such as non-Hodgkin lymphoma (NHL) and Kaposi sarcoma (KS) are significant complications. NHL in particular is not easily controlled and is a frequent AIDS-associated cause of death. Interestingly, KS has only been reported in homosexual patients, and patients with multifocal KS lesions have a poor prognosis.

The introduction of antiretroviral therapy (ART) has drastically changed the incidence of opportunistic infections in patients infected with human immunodeficiency virus 1 (HIV-1), resulting in a decline in mortality rates [2-7]. ART has decreased the frequencies of CMV, PCP, and NTM infections in patients with AIDS [7]; however, the frequency of NHL has not changed dramatically [8]. Additionally, non-AIDS-defining malignancies such as liver, lung, and gastric cancers have been observed in patients with AIDS, regardless of ART [9]. A recent study demonstrated that low CD4 counts at ART initiation was associated with a greater risk of KS and lymphoma, whereas other cancers increased over time with ART, likely reflecting an increased risk of cancer with aging [10], low CD4 counts, and cigarette smoking [11-13].

Although mortality rates have decreased dramatically with the use of ART, its effect in many patients with AIDS is limited, and AIDS-associated complications remain a leading cause of death $[14,15]$. Additionally, untreated HIV1-positive patients with severe AIDS-defining illnesses frequently visit hospitals and often rapidly succumb to suddenly aggressive progression of their illness [16,17]. Systematic pathological analysis of autopsy cases can provide useful information related to the cause of death and the distribution of pathogens in patients. However, there have been few reports describing the prevalence of infectious diseases and malignancies in autopsied patients with HIV infection $[1,18]$. A previous study using samples from autopsied patients with HIV infection during 19821998 demonstrated the prevalence of CMV, PCP, and NTM infections decreased during the study period [18]. The same study reported that, although the prevalence of KS was unchanged, the prevalence of NHL increased during the study period [18]. To the best of our knowledge, there are no reports demonstrating changes in the prevalence of opportunistic infections in autopsy cases of HIV infection following the introduction of ART after 2000.
In the present study, autopsy cases of HIV infection in Japan were retrospectively investigated to determine the prevalence of opportunistic infections and malignancies often found in patients with AIDS, including non-AIDSdefining malignancies. Additionally, the association of ART use with the prevalence of opportunistic infections and malignancies was investigated.

\section{Patients and methods \\ Patients}

The present study was approved by the Institutional Review Board of the National Institute of Infectious Diseases (Approval No. 356) and of four hospitals in Japan: Tokyo Metropolitan Komagome Hospital, National Center for Global Health and Medicine, Research Hospital, the Institute of Medical Science, the University of Tokyo, and Osaka National Hospital. Each hospital enrolled in the present study is a central hospital for AIDS treatment in Tokyo and Osaka, and has performed more than 15 autopsies of patients infected with HIV. According to a national autopsy survey by the Japan Pathology Society, 828 patients infected with HIV were autopsied in Japan from 19872009. During the period 1985-2009, 215 patients infected with HIV were autopsied at the 4 aforementioned hospitals. Thus, the number of cases in this study covered approximately $26 \%$ of all autopsied HIV cases. Ten cases autopsied in the period 2010-2012 were added to the 215 cases, making a total of 225 patients analyzed in this study (Table 1), of which $95.1 \%$ were male. The patients' ages at death ranged from 12 to 80 years, with a mean age of 44.4 years (median 44 years). Among them, $35.6 \%$ were homosexual, and $29.3 \%$ received ART (Table 1 ). The mean CD4 count at the last blood examination before death was 51.5 cells $/ \mu \mathrm{L}$ (range: $0-560$ cells $/ \mu \mathrm{L}$; median: 13.5 cells/ $\mu \mathrm{L})$. ART was introduced in Japan in 1997. In this study, ART was defined as any combination of therapy that included two nucleoside or nucleotide reverse transcriptase inhibitors plus a non-nucleoside reverse transcriptase inhibitor, protease inhibitor, or abacavir (another nucleotide reverse transcriptase inhibitor). Additionally, ART (+) patients were defined as patients who received any ART during their lifetime, whereas ART (-) patients were as patients who did not receive ART.

\section{Methods}

Pathological findings were collected from autopsy records. CMV infection was determined by the infiltration of large cells with typical inclusion bodies. Infections by other viral agents such as hepatitis B virus, herpes simplex virus, hepatitis $\mathrm{C}$ virus, JC virus (causing progressive multifocal leukoencephalopathy), and varicella zoster virus were confirmed by immunohistochemistry or polymerase chain reaction. HIV encephalopathy was defined by morphological features indicating the presence of syncytial 
Table 1 Characteristics of the patients infected with HIV

\begin{tabular}{|c|c|c|c|c|c|c|c|c|}
\hline \multirow[t]{2}{*}{ Factors } & \multirow[t]{2}{*}{ Groupings } & \multicolumn{2}{|c|}{ Total patients } & \multicolumn{2}{|c|}{ ART (-) patients } & \multicolumn{2}{|c|}{ ART (+) patients } & \multirow[t]{2}{*}{$P$ value } \\
\hline & & $\mathrm{n}$ & $\%$ & $\mathrm{n}$ & $\%$ & $\mathrm{n}$ & $\%$ & \\
\hline Total & & $225^{*}$ & $100 \%$ & 136 & $100 \%$ & 66 & $100 \%$ & \\
\hline \multirow[t]{2}{*}{ Sex } & Male & 214 & $95.1 \%$ & 128 & $94.1 \%$ & 63 & $95.5 \%$ & $0.695^{* *}$ \\
\hline & Female & 11 & $4.9 \%$ & 8 & $5.9 \%$ & 3 & $4.5 \%$ & \\
\hline \multirow[t]{10}{*}{ Age at death } & $<10$ years & 0 & $0.0 \%$ & 0 & $0.0 \%$ & 0 & $0.0 \%$ & $0.028^{* * *}$ \\
\hline & $11-20$ & 2 & $0.9 \%$ & 2 & $1.5 \%$ & 0 & $0.0 \%$ & \\
\hline & $21-30$ & 30 & $13.3 \%$ & 22 & $16.2 \%$ & 6 & $9.1 \%$ & \\
\hline & $31-40$ & 60 & $26.7 \%$ & 34 & $25.0 \%$ & 19 & $28.8 \%$ & \\
\hline & $41-50$ & 69 & $30.7 \%$ & 48 & $35.3 \%$ & 14 & $21.2 \%$ & \\
\hline & $51-60$ & 34 & $15.1 \%$ & 18 & $13.2 \%$ & 14 & $21.2 \%$ & \\
\hline & $61-70$ & 24 & $10.7 \%$ & 10 & $7.4 \%$ & 10 & $15.2 \%$ & \\
\hline & $71-80$ & 5 & $2.2 \%$ & 1 & $0.7 \%$ & 3 & $4.5 \%$ & \\
\hline & $>81$ & 0 & $0.0 \%$ & 0 & $0.0 \%$ & 0 & $0.0 \%$ & \\
\hline & Unknown & 1 & $0.4 \%$ & 1 & $0.7 \%$ & 0 & $0.0 \%$ & \\
\hline \multirow[t]{5}{*}{ Risk factor } & Homosexual & 80 & $35.6 \%$ & 52 & $38.2 \%$ & 24 & $36.4 \%$ & $0.800^{* *}$ \\
\hline & Heterosexual & 38 & $16.9 \%$ & 24 & $17.6 \%$ & 10 & $15.2 \%$ & \\
\hline & Blood product & 37 & $16.4 \%$ & 29 & $21.3 \%$ & 7 & $10.6 \%$ & \\
\hline & Other & 9 & $4.0 \%$ & 5 & $3.7 \%$ & 4 & $6.1 \%$ & \\
\hline & Unknown & 61 & $27.1 \%$ & 26 & $19.1 \%$ & 21 & $31.8 \%$ & \\
\hline \multirow[t]{7}{*}{ CD4 count before death } & $<50$ cells $/ \mu \mathrm{L}$ & 122 & $54.2 \%$ & 80 & $58.8 \%$ & 33 & $50.0 \%$ & $0.639^{* * *}$ \\
\hline & $51-100$ & 25 & $11.1 \%$ & 11 & $8.1 \%$ & 14 & $21.2 \%$ & \\
\hline & $101-200$ & 13 & $5.8 \%$ & 4 & $2.9 \%$ & 9 & $13.6 \%$ & \\
\hline & $201-300$ & 5 & $2.2 \%$ & 5 & $3.7 \%$ & 0 & $0.0 \%$ & \\
\hline & $301-400$ & 3 & $1.3 \%$ & 1 & $0.7 \%$ & 2 & $3.0 \%$ & \\
\hline & $>401$ & 4 & $1.8 \%$ & 1 & $0.7 \%$ & 3 & $4.5 \%$ & \\
\hline & Unknown & 53 & $23.6 \%$ & 34 & $25.0 \%$ & 5 & $7.6 \%$ & \\
\hline
\end{tabular}

ART, antiretroviral therapy. ART (+) patients were defined as patients who received any ART during their lifetime, whereas ART (-) patients were as patients who did not receive any ART in their lifetime.

*Total number of patients $=225$ and included 23 patients with unknown ART status.

**P values were calculated for the rates of male or homosexuals between ART $(-)$ and $(+)$ patients by Chi-square test.

***P values were calculated for age or CD4 counts between all ART (-) and (+) patients by Mann-Whitney U-test. Bold font indicates statistical significance.

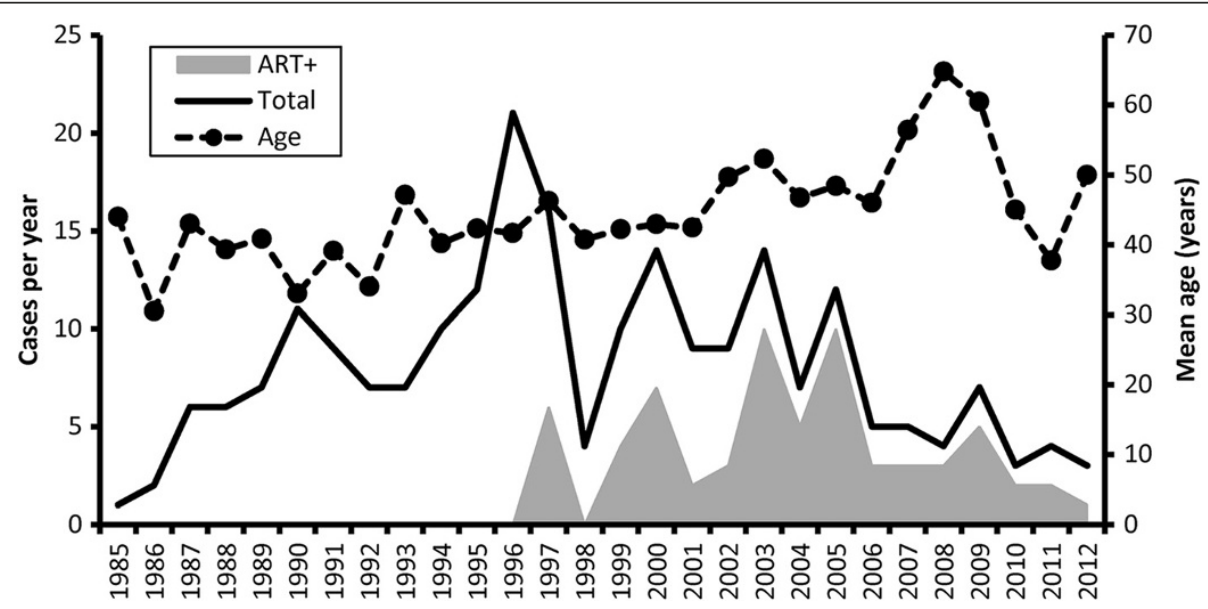

Figure 1 Annual number and mean age of AIDS-related autopsies. The solid line indicates total number of AIDS autopsies in each year. The gray area indicates the number of patients on ART in these autopsy cases. The broken bar indicates the mean age. 
giant cells and detection of HIV-1 antigen by immunohistochemistry in the brain. Bacterial infection was identified by Gram stain, and in some cases, species of bacteria were identified by bacterial cultures. Tuberculosis and NTM infection were determined by acid-fast stain and/ or PCR. Fungal and protozoan infections such as PCP, toxoplasma, Candida, Aspergillus, and Cryptococcus infection, were determined morphologically using Grocott's methenamine silver stain, periodic acid-Schiff stain, or/ and immunohistochemistry. The histological sub-typing of malignant lymphoma was based on the World Health Organization classification, fourth edition. KS was confirmed by immunohistochemistry for Kaposi sarcomaassociated herpesvirus-encoded latency-associated nuclear antigen 1 . Causes of death were determined by pathologists at each hospital based on the severity, distribution, and type of illness in the pathological findings of autopsy. Clinical data, such as age at autopsy, sex, risk factors, CD4 cell counts at the last blood examination before death, and use of ART in their lifetime were collected from medical records. Analysis of statistical significance was carried out using Mann-Whitney $U$-test for non-parametric twosample analysis and Chi-squared test for contingency table analysis.

\section{Results}

After the introduction of ART in Japan in 1997, the total number of autopsies conducted on patients with HIV infection has slowly decreased whereas the mean age at autopsy has increased slightly (Figure 1). After 1997, 66

Table 2 Infectious diseases and malignancies in AIDS-associated autopsies

\begin{tabular}{|c|c|c|c|c|c|c|c|c|}
\hline & \multicolumn{2}{|c|}{ All patients } & \multicolumn{2}{|c|}{ ART (-) patients } & \multicolumn{2}{|c|}{ ART (+) patients } & \multirow[b]{2}{*}{$P$ values } & \\
\hline & $\mathrm{n}$ & $\%$ & $\mathrm{n}$ & $\%$ & $\mathbf{n}$ & $\%$ & & \\
\hline Total & 225 & $100.0 \%$ & 136 & $100.0 \%$ & 66 & $100.0 \%$ & & \\
\hline \multicolumn{8}{|l|}{ Infectious diseases } & \\
\hline Cytomegalovirus & 142 & $63.1 \%$ & 97 & $71.3 \%$ & 25 & $37.9 \%$ & $<0.001$ & \\
\hline Pneumocystis jirovecii pneumonia & 66 & $29.3 \%$ & 43 & $31.6 \%$ & 11 & $16.7 \%$ & 0.024 & \\
\hline Non-tuberculous mycobacterium & 31 & $13.8 \%$ & 20 & $14.7 \%$ & 8 & $12.1 \%$ & 0.618 & \\
\hline Candida & 25 & $11.1 \%$ & 17 & $12.5 \%$ & 6 & $9.1 \%$ & 0.474 & \\
\hline Aspergillus & 24 & $10.7 \%$ & 17 & $12.5 \%$ & 4 & $6.1 \%$ & 0.160 & \\
\hline Human immunodeficiency virus encephalopathy & 21 & $9.3 \%$ & 13 & $9.6 \%$ & 6 & $9.1 \%$ & 0.915 & \\
\hline Cryptococcus & 16 & $7.1 \%$ & 11 & $8.1 \%$ & 3 & $4.5 \%$ & 0.526 & $Y$ \\
\hline Hepatitis B virus & 12 & $5.3 \%$ & 6 & $4.4 \%$ & 5 & $7.6 \%$ & 0.549 & Y \\
\hline Herpes simplex virus & 12 & $5.3 \%$ & 1 & $0.7 \%$ & 1 & $1.5 \%$ & 0.816 & Y \\
\hline Toxoplasmosis & 11 & $4.9 \%$ & 9 & $6.6 \%$ & 3 & $4.5 \%$ & 0.789 & Y \\
\hline Hepatitis $C$ virus & 9 & $4.0 \%$ & 3 & $2.2 \%$ & 5 & $7.6 \%$ & 0.147 & Y \\
\hline Progressive multifocal leukoencephalopathy & 8 & $3.6 \%$ & 4 & $2.9 \%$ & 2 & $3.0 \%$ & 0.684 & Y \\
\hline Tuberculosis & 6 & $2.7 \%$ & 4 & $2.9 \%$ & 0 & $0.0 \%$ & 0.385 & Y \\
\hline Varicella zoster virus & 4 & $1.8 \%$ & 2 & $1.5 \%$ & 2 & $3.0 \%$ & 0.835 & Y \\
\hline Multicentric Castleman disease & 2 & $0.9 \%$ & 1 & $0.7 \%$ & 1 & $1.5 \%$ & 0.816 & Y \\
\hline \multicolumn{8}{|l|}{ Malignancies } & \\
\hline Non Hodgkin lymphoma & 71 & $31.6 \%$ & 41 & $30.1 \%$ & 25 & $37.9 \%$ & 0.272 & \\
\hline Kaposi sarcoma & 38 & $16.9 \%$ & 22 & $16.2 \%$ & 10 & $15.2 \%$ & 0.852 & \\
\hline Endocervical cancer & 0 & $0.0 \%$ & 0 & $0.0 \%$ & 0 & $0.0 \%$ & - & \\
\hline Non-AIDS defining malignancies & 20 & $8.9 \%$ & 10 & $7.4 \%$ & 10 & $15.2 \%$ & 0.082 & \\
\hline Hepatic cancer & 8 & $3.6 \%$ & 4 & $2.9 \%$ & 4 & $6.1 \%$ & 0.495 & Y \\
\hline Lung cancer & 6 & $2.7 \%$ & 2 & $1.5 \%$ & 4 & $6.1 \%$ & 0.174 & Y \\
\hline Leukemia & 2 & $0.9 \%$ & 0 & $0.0 \%$ & 2 & $3.0 \%$ & 0.200 & Y \\
\hline Hodgkin lymphoma & 2 & $0.9 \%$ & 1 & $0.7 \%$ & 1 & $1.5 \%$ & 0.816 & Y \\
\hline Gastric cancer & 1 & $0.4 \%$ & 1 & $0.7 \%$ & 0 & $0.0 \%$ & 0.711 & Y \\
\hline Other cancer & 3 & $1.3 \%$ & 3 & $2.2 \%$ & 0 & $0.0 \%$ & 0.551 & Y \\
\hline
\end{tabular}

$P$ values were calculated by Chi-square test. $Y$ indicates the use of Chi-square test with Yates correction. Bold font indicates statistical significance. ART, antiretroviral therapy. Because more than one illness was detected in patients, the numbers of all illness are greater than the total number. 
of 126 patients (52.6\%) received ART during their lifetime. The mean age at death of patients on ART was 47.3 years, which was significantly higher than that of ART naïve patients (42.6 years; $P=0.028$; Mann-Whitney $U$-test). Mean CD4 counts of ART $(-)$ and $(+)$ patients at the last blood examination before death were not significantly different $(39.6$ and 77.0 cells $/ \mu \mathrm{L}$, respectively, $P=0.63$, Mann-Whitney $U$-test).

CMV was the most commonly identified pathogen among the autopsy cases (Table 2) and was detected in various organs, the most frequent being the adrenal gland (Figure 2A). PCP and NTM were also common pathogens found in the lungs of autopsied patients. Candida albicans was frequently detected in the gastrointestinal tract and oral cavity (Figure 2B). The prevalence of CMV and PCP was significantly lower in ART (+) patients than in ART (-) patients (Table 2). There was no significant difference in the prevalence of other opportunistic infections such as NTM and Candida or prevalence of HIV encephalopathy between ART (+) and (-) patients (Table 2).

Malignancies were identified in 50.2\% (113/225) of all cases (Table 2). NHL was the most frequent malignancy with a lower prevalence in ART (-) patients (30.1\%) than ART (+) patients (37.9\%); however, the difference was not significant (Table 2). Diffuse large B-cell lymphoma was the most frequent histological subtype of NHL followed by Burkitt lymphoma, primary effusion lymphoma, and plasmablastic lymphoma (Table 3). Epstein-Barr virus positivity in lymphoma cases was significantly lower in ART (+) patients compared with ART $(-)$ patients $(P=0.001$, Chisquare test). KS was frequently found in the skin as well as other sites such as the gastrointestinal tract upon autopsy. In addition to NHL and KS, non-AIDS-defining malignancies such as Hodgkin lymphoma (HL), hepatic cancer, lung cancer, and leukemia were also observed in 20 patients. The prevalence of non-AIDS-defining malignancies was higher in ART (+) patients compared with ART (-) patients (Table 2).

The lung was the most frequent target for pathogens in patients with AIDS and 173 (76.9\%) autopsy cases demonstrated the presence of lung-related illnesses (Table 4), which were significantly more frequent in ART (-) patients $(112 / 136,82.4 \%)$ than ART (+) patients (42/66, 63.6\%) $(P=0.003$, Chi-square test). CMV then PCP was the most frequently observed lung-related illnesses. The brain was the second most frequently affected organ in the autopsy cases. Although the brain was not investigated in 53 autopsies, 85 of the remaining 172 cases (49.4\%) had brain-related illnesses, with CMV infection the most common, followed by lymphoma and HIV encephalopathy (Table 5). However, there was no significant difference in the rate of brain-related illnesses in ART (+) (37.8\%, 17 of 45$)$ or ART $(-)$ patients $(52.7 \%, 58 / 110)(P=0.091$, Chi-square test).

We also investigated the direct causes of death in the autopsied patients (Table 6). Lymphoma was the most frequent cause of death, followed by CMV infection. Non AIDS-defining cancers as a cause of death were significantly different between ART (-) $(2,1.5 \%)$ and ART (+) patients $(6,9.1 \%)(P=0.026$; Chi-square test with Yates correction). The prevalence of CMV, pneumonia, PCP, and NTM as a cause of death were lower in ART (+) patients compared with ART (-) patients, but no significant differences were observed between the groups.

\section{Discussion}

In the present study, we measured the prevalence of infectious disease and malignancy in autopsy cases of
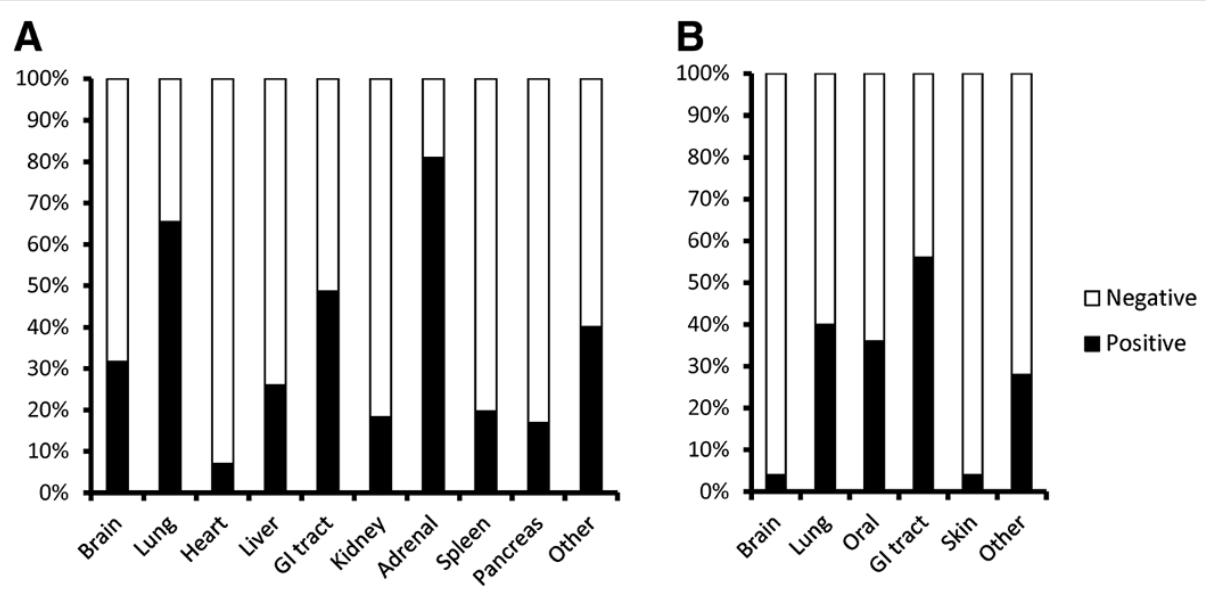

Figure 2 Distribution of cytomegalovirus and Candida albicans. (A) CMV positive rate in each organ. Black bar indicates the CMV positive rate in each organ from 142 CMV-positive patients. Because CMV was detected in more than one organ per patient, the sum of the black bars is over 100\%. (B) The positive rate of Candida albicans in each organ. Black bar indicates the positive rate of Candida albicans per organ from 25 Candida albicans-positive patients. 
Table 3 Non-Hodgkin lymphoma and Kaposi sarcoma in AIDS-associated autopsies

\begin{tabular}{|c|c|c|c|c|c|c|c|c|c|}
\hline & & \multicolumn{2}{|c|}{ Total } & \multicolumn{2}{|c|}{ ART (-) patients } & \multicolumn{2}{|c|}{ ART (+) patients } & \multicolumn{2}{|c|}{$P$ values } \\
\hline & & $\mathrm{n}$ & $\%$ & $n$ & $\%$ & $\mathrm{n}$ & $\%$ & & \\
\hline All NHL cases & & 71 & $100.0 \%$ & 41 & $100.0 \%$ & 25 & $100.0 \%$ & & \\
\hline \multirow[t]{6}{*}{ Histology } & DLBCL & 53 & $74.6 \%$ & 30 & $73.2 \%$ & 18 & $72.0 \%$ & 0.917 & \\
\hline & $B L$ & 4 & $5.6 \%$ & 3 & $7.3 \%$ & 1 & $4.0 \%$ & 0.987 & $Y$ \\
\hline & PEL & 5 & $7.0 \%$ & 4 & $9.8 \%$ & 1 & $4.0 \%$ & 0.706 & Y \\
\hline & PBL & 1 & $1.4 \%$ & 1 & $2.4 \%$ & 0 & $0.0 \%$ & 0.801 & Y \\
\hline & Other & 6 & $8.5 \%$ & 2 & $4.9 \%$ & 4 & $16.0 \%$ & 0.279 & Y \\
\hline & Unknown & 2 & $2.8 \%$ & 1 & $2.4 \%$ & 1 & $4.0 \%$ & 0.703 & Y \\
\hline \multirow[t]{4}{*}{ Site } & Nodular & 1 & $1.4 \%$ & 0 & $0.0 \%$ & 1 & $4.0 \%$ & 0.801 & Y \\
\hline & Extranodular & 45 & $63.4 \%$ & 28 & $68.3 \%$ & 12 & $48.0 \%$ & 0.102 & \\
\hline & Both & 21 & $29.6 \%$ & 11 & $26.8 \%$ & 10 & $40.0 \%$ & 0.265 & \\
\hline & Unknown & 4 & $5.6 \%$ & 2 & $4.9 \%$ & 2 & $8.0 \%$ & 0.987 & $Y$ \\
\hline PCNS & Yes & 27 & $38.0 \%$ & 18 & $43.9 \%$ & 6 & $24.0 \%$ & 0.103 & \\
\hline EBV & Positive & 52 & $73.2 \%$ & 35 & $85.4 \%$ & 12 & $48.0 \%$ & 0.001 & \\
\hline KSHV & Positive & 6 & $8.5 \%$ & 5 & $12.2 \%$ & 1 & $4.0 \%$ & 0.495 & Y \\
\hline Cause of death & Yes & 50 & $70.4 \%$ & 33 & $80.5 \%$ & 16 & $64.0 \%$ & 0.137 & \\
\hline All KS cases & & 38 & & 22 & & 10 & & & \\
\hline \multirow[t]{5}{*}{ Site } & Skin & 32 & $84.2 \%$ & 19 & $86.4 \%$ & 9 & $90.0 \%$ & 0.410 & \\
\hline & Gl tract & 27 & $71.1 \%$ & 15 & $68.2 \%$ & 8 & $80.0 \%$ & 0.705 & \\
\hline & Lung & 21 & $55.3 \%$ & 11 & $50.0 \%$ & 6 & $60.0 \%$ & 0.799 & \\
\hline & Lymph node & 20 & $52.6 \%$ & 13 & $59.1 \%$ & 6 & $60.0 \%$ & 0.502 & \\
\hline & Other & 16 & $42.1 \%$ & 0 & $0.0 \%$ & 0 & $0.0 \%$ & 0.787 & Y \\
\hline Cause of death & Yes & 11 & $29.0 \%$ & 7 & $31.8 \%$ & 2 & $20.0 \%$ & 0.791 & Y \\
\hline
\end{tabular}

$\mathrm{NHL}$, Non-Hodgkin lymphoma; DLBCL, diffuse large B-cell lymphoma; BL, Burkitt lymphoma; PEL, primary effusion lymphoma; PBL, plasmablastic lymphoma; PCNS, primary central nervous system lymphoma; EBV, Epstein-Barr virus; KSHV, Kaposi sarcoma-associated herpes virus; KS, Kaposi sarcoma; GI, gastrointestinal. $P$ values were calculated by Chi-square test. $\mathrm{Y}$ indicates the use of Chi-square test with Yates correction. Bold font indicates statistical significance.

Table 4 Lung disease in patients infected with HIV

\begin{tabular}{lcc}
\hline Illness & $\mathbf{n}$ & $\begin{array}{c}\text { \% of total patients } \\
\text { (n = 225) }\end{array}$ \\
\hline Any illness & 173 & $76.9 \%$ \\
Cytomegalovirus infection & 93 & $41.3 \%$ \\
Pneumocystis jirovecii pneumonia & 66 & $29.3 \%$ \\
Any bacterial pneumonia & 31 & $13.8 \%$ \\
Aspergillus infection & 23 & $10.2 \%$ \\
Kaposi sarcoma & 21 & $9.3 \%$ \\
Non-tuberculous mycobacterium infection & 14 & $6.2 \%$ \\
Cryptococcosis & 11 & $4.9 \%$ \\
Candida infection & 10 & $4.4 \%$ \\
Tuberculosis & 4 & $1.8 \%$ \\
\hline
\end{tabular}

Because more than one illness was detected in patients, the numbers of all illness are greater than the total number.
HIV-infected patients identified from 1985-2012 at four central hospitals in Japan. CMV infection, PCP, NTM infection, NHL, and KS were frequently observed in the autopsy cases. The prevalence of CMV and PCP was lower in ART (-) patients compared with ART (+) patients. The prevalence of non-AIDS defining malignancies was higher among ART (+) patients than ART (-) patients, suggesting that the onset of various opportunistic infections and malignancies should be carefully monitored regardless of whether the patient is receiving ART.

The autopsy cases in the present study were predominantly male (95.1\%, Table 1). Additionally, more than $70 \%$ of the autopsy cases in the present study had a CD4 count $<200$ cells $/ \mu \mathrm{L}$ at the last blood examination before death (Table 1). A recent clinical study demonstrated the incidence of AIDS-defining illnesses in patients with HIV infection was decreased by the introduction of ART, especially in patients with CD4 counts $>200$ cells $/ \mu \mathrm{L}$ [2]. Thus, our findings at autopsy cannot be compared with previous clinical studies because many clinical study patients had a high range of CD4 counts and ART responses. Interestingly, there was no significant difference in the 
Table 5 Brain disease in patients infected with HIV

\begin{tabular}{lcc}
\hline Illness & $\mathbf{n}$ & $\begin{array}{c}\text { \% in total } \\
\text { autopsied brains } \\
\text { (n= 172) }\end{array}$ \\
\hline Any illness & 85 & $49.4 \%$ \\
Cytomegalovirus infection & 45 & $26.1 \%$ \\
Malignant lymphoma & 26 & $15.1 \%$ \\
HIV encephalopathy & 21 & $12.2 \%$ \\
Progressive multifocal & 8 & $4.7 \%$ \\
leukoencephalopathy & 8 & $4.7 \%$ \\
Toxoplasmosis & 4 & $2.3 \%$ \\
Non-tuberculous & & \\
mycobacterium infection & 2 & $1.2 \%$ \\
Aspergillus infection & 2 & $1.2 \%$ \\
Varicella zoster virus infection & 1 & $0.6 \%$ \\
Herpes simplex virus infection & 1 & $0.6 \%$ \\
Glioblastoma & 1 & $0.6 \%$ \\
Candida infection &
\end{tabular}

Because more than one illness was detected in patients, the numbers of all illness are greater than the total number. cause of death between ART $(+)$ and $(-)$ patients, with the exception of those with cancer (Table 6), indicating the prevalence of lethal illness did not differ between ART $(+)$ and $(-)$ patients.

Malignancies were frequent causes of death in the present study regardless of ART status (Table 6). Several studies demonstrated that the introduction of ART reduced the incidence of NHL in patients with HIV infection [13,15,19-23]. The use of ART has also been associated with a decrease in the incidence of KS $[15,24,25]$. However, an association between the incidence of non-AIDS-defining cancers and ART remains controversial. An increase of non-AIDS-defining cancers in patients receiving ART was shown in previous clinical reports [26,27], but a separate study showed that, with the exception of long-term protease inhibitor usage, ART exposure was generally not associated with a risk of non-AIDS-defining cancers [28]. The reasons for increased risk of non-AIDS-defining cancers in patients on ART are unclear, but might reflect the concomitant increase of the mean age at autopsy during the study period. This suggests that life extension of HIV-infected patients by ART results in the increased chance of developing non-AIDS events and malignancies. It was also

Table 6 Cause of death in AIDS-associated autopsies

\begin{tabular}{|c|c|c|c|c|c|c|c|c|}
\hline & \multicolumn{2}{|c|}{ All } & \multicolumn{2}{|c|}{ ART (-) patients } & \multicolumn{2}{|c|}{ ART (+) patients } & \multirow[b]{2}{*}{$P$ values } & \\
\hline & $\mathrm{n}$ & $\%$ & $n$ & $\%$ & $\mathbf{n}$ & $\%$ & & \\
\hline Total* & 225 & $100.0 \%$ & 136 & $100.0 \%$ & 66 & $100.0 \%$ & & \\
\hline Malignant lymphoma & 50 & $22.2 \%$ & 33 & $24.3 \%$ & 16 & $24.2 \%$ & 0.997 & \\
\hline Cytomegalovirus & 44 & $19.6 \%$ & 27 & $19.9 \%$ & 9 & $13.6 \%$ & 0.279 & \\
\hline Pneumonia & 31 & $13.8 \%$ & 19 & $14.0 \%$ & 9 & $13.6 \%$ & 0.949 & \\
\hline Pneumocystis jirovecii pneumonia & 30 & $13.3 \%$ & 21 & $15.4 \%$ & 4 & $6.1 \%$ & 0.058 & \\
\hline Non-tuberculous mycobacterium & 12 & $5.3 \%$ & 10 & $7.4 \%$ & 2 & $3.0 \%$ & 0.367 & $Y$ \\
\hline Kaposi sarcoma & 11 & $4.9 \%$ & 7 & $5.1 \%$ & 2 & $3.0 \%$ & 0.749 & Y \\
\hline Progressive multifocal leukoencephalopathy & 8 & $3.6 \%$ & 4 & $2.9 \%$ & 2 & $3.0 \%$ & 0.684 & Y \\
\hline Cancer & 8 & $3.6 \%$ & 2 & $1.5 \%$ & 6 & $9.1 \%$ & 0.026 & Y \\
\hline Hepatitis & 8 & $3.6 \%$ & 3 & $2.2 \%$ & 4 & $6.1 \%$ & 0.320 & Y \\
\hline Cryptococcus & 7 & $3.1 \%$ & 6 & $4.4 \%$ & 0 & $0.0 \%$ & 0.197 & Y \\
\hline Kidney failure & 7 & $3.1 \%$ & 4 & $2.9 \%$ & 3 & $4.5 \%$ & 0.861 & Y \\
\hline HIV encephalopathy & 7 & $3.1 \%$ & 5 & $3.7 \%$ & 2 & $3.0 \%$ & 0.861 & Y \\
\hline Aspergillus & 6 & $2.7 \%$ & 5 & $3.7 \%$ & 0 & $0.0 \%$ & 0.274 & Y \\
\hline Toxoplasmosis & 4 & $1.8 \%$ & 3 & $2.2 \%$ & 1 & $1.5 \%$ & 0.835 & Y \\
\hline Tuberculosis & 3 & $0.9 \%$ & 2 & $1.5 \%$ & 0 & $0.0 \%$ & 0.816 & Y \\
\hline Sepsis & 3 & $1.3 \%$ & 2 & $1.5 \%$ & 1 & $1.5 \%$ & 0.551 & Y \\
\hline Candida & 3 & $1.3 \%$ & 2 & $1.5 \%$ & 0 & $0.0 \%$ & 0.816 & Y \\
\hline Varicella zoster virus & 2 & $1.3 \%$ & 1 & $0.7 \%$ & 1 & $1.5 \%$ & 0.816 & Y \\
\hline Nocardia & 1 & $0.4 \%$ & 1 & $0.7 \%$ & 0 & $0.0 \%$ & 0.711 & Y \\
\hline Histoplasma & 1 & $0.4 \%$ & 1 & $0.7 \%$ & 0 & $0.0 \%$ & 0.711 & Y \\
\hline
\end{tabular}

*Because more than one illness was detected in patients, the numbers of all illness are greater than the total number.

HIV, human immunodeficiency virus. $P$ values were calculated with the Chi-square test. $Y$ indicates the use of Chi-square test with Yates correction. Bold font indicates statistical significance. 
demonstrated that ART introduction changed the pathological features of lymphoma; for example, a decrease of Epstein-Barr virus-positive lymphoma in Japanese patients with AIDS was reported [29]. Although HL was rare in the general Japanese population compared with European countries and the United States [30], the incidence of HL increased in Japanese patients on ART [17]. Thus, the increased risk of malignancies during the clinical course of HIV infection in patients receiving ART was reflected as a cause of death in the autopsy cases used in our study.

The prevalence of opportunistic infections differs among various regions and countries. In sub-Saharan African countries, more than $80 \%$ of HIV-positive patients die of infectious diseases, with disseminated tuberculosis being the most common (36\%) [31]. Furthermore, there was no difference in the type of disease HIV patients succumbed to, regardless of ART status. In the USA and European countries, tuberculosis/NTM represented $<10 \%$ of mortality in autopsy cases after 1996 [18]. In this study, tuberculosis was detected in only $2.7 \%$ of Japanese autopsy cases, but was the cause of death for $50 \%$ of afflicted patients. Mortality by PCP has decreased worldwide in patients with AIDS owing to prophylactic administration of an anti-PCP drug [16]. PCP was found in 36.4\% (36/99 cases) of patients with AIDS before 1997, but was significantly reduced after 1997 (23.8\%; 30/126 cases; $P=0.04$; Chi-square test). This suggests that the decrease in PCP cases is associated with ART and anti-PCP prophylaxis.

Our study had several limitations. Bacterial culture was not available in this study owing to the use of formalinfixed paraffin-embedded samples, and it was therefore difficult to identify the bacterial species responsible for many cases of pneumonia. Additionally, clinical information was limited. Information on HIV-RNA, an important indicator of ART effects, was not available for these patients. In addition, information regarding CD4 counts and the type, duration and possible interruption of ART were not available for a subset of patients. Therefore, we could not identify cases of immune reconstitution syndrome. Age at seroconversion and time living with HIV are also major predictors of HIV disease progression, however information of these parameters was limited. Thus, it should be noted that the conclusions in this study cannot be generally applied to the current HIV positive population in Japan. Furthermore, all findings in this study were obtained from autopsies.

\section{Conclusions}

Although further studies are required to demonstrate the association between ART and illness identified at autopsy, the present study demonstrates the prevalence of infectious diseases and malignancies in autopsy cases of HIV infection in Japan. While the prevalence of CMV infection and PCP at autopsy were lower in ART $(+)$ patients than
ART (-) patients, non-AIDS-defining malignancies were observed as a cause of death more frequently in ART $(+)$ patients than ART (-) patients.

\section{Abbreviations}

HIV: Human immunodeficiency virus; ART: Antiretroviral therapy;

AIDS: Acquired immunodeficiency syndrome; PCP: Pneumocystis jirovecii pneumonia; CMV: Cytomegalovirus; NTM: Non-tuberculous mycobacteria; NHL: Non-Hodgkin lymphoma; KS: Kaposi sarcoma.

\section{Competing interests}

The authors declare no conflicts of interests.

\section{Authors' contributions}

HK, S Okada and AY conceived this study; TH, MM, YKod, NO, YO, SM, TI, HH, and $\mathrm{HK}$ performed the autopsies, pathological analyses and reviews; $\mathrm{AA}, \mathrm{KT}$, JT, YKi, TU, TS, TK, Al, and S Oka collected clinical data; HK analyzed the data, performed statistical analyses, and drafted the manuscript. All authors read and approved the final manuscript.

\section{Acknowledgements}

This work was partly supported by Health and Labour Sciences Research Grants [No. H22-AIDS-I-002, H23-AIDS-I-002, H24-AIDS-I-003, and H25-AIDS-I002] from the Ministry of Health, Labour and Welfare and Grants-in-Aid for Scientific Research from the Ministry of Education, Culture, Sports, Science and Technology of Japan [No. 24659212 to HK]. The authors are indebted to the following investigators for contributing clinical data and providing excellent suggestions: Drs. Nobuaki Funata, Yuuko Yamada, Fumiaki Imamura, Akihiko Suganuma, Naoki Yanagisawa, Tokyo Metropolitan Komagome Hospital; Mr. Toshio Kitazawa, Department of Pathology, National Center for Global Health and Medicine Hospital; Dr. Takashi Odawara, Department of Infectious Diseases, Institute of Medical Science, University of Tokyo; Drs. Yasuharu Nishida, Dai Watanabe, Keishiro Yajima, Yoshihiko Ogawa, Yusuke Koizumi, Kazuyuki Hirota, Hitoshi Yonemoto, Hiroshi Otera, Daisuke Kasai, Motoko Ikuma, Masayuki Mano, Kiyoshi Mori, and Yukiko Morinaga, Osaka National Hospital.

\section{Author details}

${ }^{1}$ Department of Pathology, National Institute of Infectious Diseases, 1-23-1 Toyama, Shinjuku-ku, Tokyo 162-8640, Japan. ${ }^{2}$ Department of Pathology, Tokyo Metropolitan Komagome Hospital, 3-18-22 Honkomagome, Bunkyo-ku, Tokyo 113-8677, Japan. ${ }^{3}$ Department of Pathology, National Center for Global Health and Medicine Hospital, 1-21-1 Toyama, Shinjuku-ku, Tokyo 162-8655, Japan. ${ }^{4}$ Department of Pathology, Kyorin University School of Medicine, 6-20-2 Shinkawa, Mitaka City, Tokyo 181-8611, Japan. ${ }^{5}$ Department of Pathology, Osaka National Hospital, 2-1-14 Hoenzaka, Chuo-ku, Osaka 540-0006, Japan. ${ }^{6}$ Department of Pathology, Research Hospital, the Institute of Medical Science, the University of Tokyo, 4-6-1 Shirokanedai, Minato-ku, Tokyo 108-8639, Japan. ${ }^{7}$ Department of Infectious Diseases, Tokyo Metropolitan Komagome Hospital, 3-18-22 Honkomagome, Bunkyo-ku, Tokyo 113-8677, Japan. ${ }^{8}$ AIDS Clinical Center, National Center for Global Health and Medicine Hospital, 1-21-1 Toyama, Shinjuku-ku, Tokyo 162-8655, Japan. ${ }^{9}$ Department of Infectious Diseases, Osaka National Hospital, 2-1-14 Hoenzaka, Chuo-ku, Osaka 540-0006, Japan. ${ }^{10}$ Department of Infectious Diseases and Applied Immunology, Hospital, the Institute of Medical Science, the University of Tokyo, 4-6-1 Shirokanedai, Minato-ku, Tokyo 108-8639, Japan. ${ }^{11}$ Division of Infectious Diseases, Advanced Clinical Research Center, the Institute of Medical Science, the University of Tokyo, 4-6-1 Shirokanedai, Minato-ku, Tokyo 108-8639, Japan. ${ }^{12}$ Center for AIDS Research, Kumamoto University, 2-2-1 Honjo, Kumamoto 860-0811, Japan. ${ }^{13}$ Oomura City Municipal Hospital, 133-2 Kogashima-cho, Omura City, Nagasaki 865-8561, Japan.

Received: 17 October 2013 Accepted: 25 April 2014

Published: 29 April 2014

\section{References}

1. Bruno R, Sacchi P, Filice G: Overview on the incidence and the characteristics of HIV-related opportunistic infections and neoplasms of the heart: impact of highly active antiretroviral therapy. AIDS 2003, 17(Suppl 1):S83-S87.

2. Mocroft A, Furrer HJ, Miro JM, Reiss P, Mussini C, Kirk O, Abgrall S, Ayayi S, Bartmeyer B, Braun D, Castagna A, d'Arminio Monforte A, Gazzard B, Gutierrez F, Hurtado I, Jansen K, Meyer L, Munoz P, Obel N, Soler-Palacin P, 
Papadopoulos A, Raffi F, Ramos JT, Rockstroh JK, Salmon D, Torti C, Warszawski J, de Wit S, Zangerle R, Fabre-Colin C, et al: The Incidence of AIDS-Defining Illnesses at a Current CD4 Count $>=200$ Cells $/ \mu \mathrm{L}$ in the Post-Combination Antiretroviral Therapy Era. Clin Infect Dis 2013, 57:1038-1047

3. Mocroft A, Katlama C, Johnson AM, Pradier C, Antunes F, Mulcahy F, Chiesi A, Phillips AN, Kirk O, Lundgren JD: AIDS across Europe, 1994-98: the EuroSIDA study. Lancet 2000, 356:291-296.

4. Palella FJ Jr, Delaney KM, Moorman AC, Loveless MO, Fuhrer J, Satten GA, Aschman DJ, Holmberg SD: Declining morbidity and mortality among patients with advanced human immunodeficiency virus infection. HIV Outpatient Study Investigators. N Engl J Med 1998, 338:853-860.

5. Egger M, Hirschel B, Francioli P, Sudre P, Wirz M, Flepp M, Rickenbach M, Malinverni R, Vernazza P, Battegay M: Impact of new antiretroviral combination therapies in HIV infected patients in Switzerland: prospective multicentre study. Swiss HIV Cohort Study. BMJ 1997, 315:1194-1199.

6. Young J, Psichogiou M, Meyer L, Ayayi S, Grabar S, Raffi F, Reiss P, Gazzard B, Sharland M, Gutierrez F, Obel N, Kirk O, Miro JM, Furrer H, Castagna A, De Wit S, Munoz J, Kjaer J, Grarup J, Chene G, Bucher H: CD4 cell count and the risk of AIDS or death in HIV-Infected adults on combination antiretroviral therapy with a suppressed viral load: a longitudinal cohort study from COHERE. PLoS Med 2012, 9:e1001194.

7. Buchacz K, Baker RK, Palella FJ Jr, Chmiel JS, Lichtenstein KA, Novak RM, Wood KC, Brooks JT, HOPS-Investigators: AIDS-defining opportunistic illnesses in US patients, 1994-2007: a cohort study. AIDS 2010, 24:1549-1559.

8. Ives NJ, Gazzard BG, Easterbrook PJ: The changing pattern of AIDS-defining illnesses with the introduction of highly active antiretroviral therapy (HAART) in a London clinic. J Infect 2001, 42:134-139.

9. Silverberg MJ, Chao C, Leyden WA, Xu L, Tang B, Horberg MA, Klein D, Quesenberry CP Jr, Towner WJ, Abrams DI: HIV infection and the risk of cancers with and without a known infectious cause. AIDS 2009, 23:2337-2345

10. Yanik EL, Napravnik S, Cole SR, Achenbach CJ, Gopal S, Olshan A, Dittmer DP, Kitahata MM, Mugavero MJ, Saag M, Moore RD, Mayer K, Mathews WC, Hunt PW, Rodriguez B, Eron JJ: Incidence and timing of cancer in HIV-infected individuals following initiation of combination antiretroviral Therapy. Clin Infect Dis 2013, 57:756-764.

11. Guiguet M, Boue F, Cadranel J, Lang JM, Rosenthal E, Costagliola D: Effect of immunodeficiency, HIV viral load, and antiretroviral therapy on the risk of individual malignancies (FHDH-ANRS CO4): a prospective cohort study. Lancet Oncol 2009, 10:1152-1159.

12. Reekie J, Kosa C, Engsig F, Monforte A, Wiercinska-Drapalo A, Domingo P, Antunes F, Clumeck N, Kirk O, Lundgren JD, Mocroft A: Relationship between current level of immunodeficiency and non-acquired immunodeficiency syndrome-defining malignancies. Cancer 2010, 116:5306-5315.

13. Clifford GM, Polesel J, Rickenbach M, Dal Maso L, Keiser O, Kofler A, Rapiti E, Levi F, Jundt G, Fisch T, Bordoni A, De Weck D, Franceschi S: Cancer risk in the Swiss HIV Cohort Study: associations with immunodeficiency, smoking, and highly active antiretroviral therapy. I Natl Cancer Inst 2005, 97:425-432.

14. Lim P-L, Zhou J, Ditangco R, Law M, Sirisanthana T, Kumarasamy N, Chen Y-M, Phanuphak P, Lee CKC, Saphonn V, Oka S, Zhang F, Choi J, Pujari S, Kamarulzaman A, Li PCK, Merati T, Yunihastuti E, Messerschmidt L, Sungkanuparph S: Failure to prescribe pneumocystis prophylaxis is associated with increased mortality, even in the CART era: results from the Treat Asia HIV observational database. J Int AIDS Soc 2012, 15:1-1.

15. Yotsumoto M, Hagiwara S, Ajisawa A, Tanuma J, Uehira T, Nagai H, Fujikawa Y, Maeda S, Kitano K, Arima N, Uno K, Iwai T, Hongo I, Ota Y, Fukutake K, Okada S: Clinical characteristics of human immunodeficiency virus-associated Hodgkin lymphoma patients in Japan. Int J Hematol 2012, 96:247-253.

16. Hashimoto S, Matsumoto T, Nagai M, Matsuyama Y, Nakamura Y, Umeda T, Kamakura M, Ichikawa S, Kimura S, Fukutomi K, Kihara M: Delays and continuation of hospital visits among HIV-infected persons and AIDS cases in Japan. J Epidemiol 2000, 10:65-70.

17. Nakamura H, Teruya K, Takano M, Tsukada K, Tanuma J, Yazaki H, Honda H, Honda M, Gatanaga H, Kikuchi Y, Oka S: Clinical symptoms and courses of primary HIV-1 infection in recent years in Japan. Intern Med 2011, 50:95-101.

18. Masliah E, DeTeresa RM, Mallory ME, Hansen LA: Changes in pathological findings at autopsy in AIDS cases for the last 15 years. AIDS 2000, 14:69-74.
19. Tirelli U, Spina M, Gaidano G, Vaccher E, Franceschi S, Carbone A: Epidemiological, biological and clinical features of HIV-related lymphomas in the era of highly active antiretroviral therapy. AIDS 2000, 14:1675-1688.

20. Kirk O, Pedersen C, Cozzi-Lepri A, Antunes F, Miller V, Gatell JM, Katlama C Lazzarin A, Skinhoj P, Barton SE: Non-Hodgkin lymphoma in HIV-infected patients in the era of highly active antiretroviral therapy. Blood 2001, 98:3406-3412.

21. Carrieri MP, Pradier C, Piselli P, Piche M, Rosenthal E, Heudier P, Durant J, Serraino D: Reduced incidence of Kaposi's sarcoma and of systemic non-hodgkin's lymphoma in HIV-infected individuals treated with highly active antiretroviral therapy. Int J Cancer 2003, 103:142-144.

22. Vilchez RA, Jorgensen JL, Kroll MH: Systemic non-Hodgkin lymphoma in HIV-infected patients in the era of highly active antiretroviral therapy. Blood 2002, 99:4250-4251.

23. Wolf T, Brodt HR, Fichtlscherer S, Mantzsch K, Hoelzer D, Helm EB, Mitrou PS, Chow KU: Changing incidence and prognostic factors of survival in AIDS-related non-Hodgkin's lymphoma in the era of highly active antiretroviral therapy (HAART). Leuk Lymphoma 2005, 46:207-215.

24. Pipkin S, Scheer S, Okeigwe I, Schwarcz S, Harris DH, Hessol NA: The effect of HAART and calendar period on Kaposi's sarcoma and non-Hodgkin lymphoma: results of a match between an AIDS and cancer registry. AIDS 2011, 25:463-471.

25. Franceschi S, Lise M, Clifford GM, Rickenbach M, Levi F, Maspoli M, Bouchardy C, Dehler S, Jundt G, Ess S, Bordoni A, Konzelmann I, Frick H, Dal Maso L, Elzi L, Furrer H, Calmy A, Cavassini M, Ledergerber B, Keiser O: Changing patterns of cancer incidence in the early- and late-HAART periods: the Swiss HIV Cohort Study. Br J Cancer 2010, 103:416-422.

26. Powles T, Robinson D, Stebbing J, Shamash J, Nelson M, Gazzard B, Mandelia S, Moller H, Bower M: Highly active antiretroviral therapy and the incidence of non-AIDS-defining cancers in people with HIV infection. J Clin Oncol 2009, 27:884-890.

27. Hagiwara S, Yotsumoto M, Odawara T, Ajisawa A, Uehira T, Nagai H, Tanuma J, Okada S: Non-AIDS-defining hematological malignancies in HIV-infected patients: an epidemiological study in Japan. AIDS 2013, 27:279-283.

28. Chao C, Leyden WA, Xu L, Horberg MA, Klein D, Towner WJ, Quesenberny CP Jr, Abrams DI, Silverberg MJ: Exposure to antiretroviral therapy and risk of cancer in HIV-infected persons. AIDS 2012, 26:2223-2231.

29. Hishima T, Oyaizu N, Fujii T, Tachikawa N, Ajisawa A, Negishi M, Nakamura T, Iwamoto A, Hayashi Y, Matsubara D, Sasao Y, Kimura S, Kikuchi Y, Teruya K, Yasuoka A, Oka S, Saito K, Mori S, Funata N, Sata T, Katano H: Decrease in Epstein-Barr virus-positive AIDS-related lymphoma in the era of highly active antiretroviral therapy. Microbes Infect 2006, 8:1301-1307.

30. Levi F, Lucchini F, Negri E, Boyle P, La Vecchia C: Trends in mortality from Hodgkin's disease in Western and Eastern Europe. Br J Cancer 2002, 87:291-293

31. Cox JA, Lukande RL, Nelson AM, Mayanja-Kizza H, Colebunders R, Van Marck E, Manabe YC: An autopsy study describing causes of death and comparing clinico-pathological findings among hospitalized patients in Kampala, Uganda. PLoS One 2012, 7:e33685.

doi:10.1186/1471-2334-14-229

Cite this article as: Katano et al:: The prevalence of opportunistic infections and malignancies in autopsied patients with human immunodeficiency virus infection in Japan. BMC Infectious Diseases 2014 14:229.

\section{Submit your next manuscript to BioMed Central and take full advantage of:}

- Convenient online submission

- Thorough peer review

- No space constraints or color figure charges

- Immediate publication on acceptance

- Inclusion in PubMed, CAS, Scopus and Google Scholar

- Research which is freely available for redistribution 